\title{
Correspondence
}

\section{Revised Gairdner-Pearson growth charts}

Sir,

Since 1971 when these charts were published, ${ }^{1}$ ultrasonography has enabled gestational age to be assessed more reliably. Recent observations by Keen ${ }^{2}$ in Sheffield give birthweight for the period 14 to 42 weeks' gestation. Between 32 and 36 weeks these values are significantly lower than those shown in our graphs, which were derived from data collected in Aberdeen between 1948 and 1964.

Other recent observations on birthweight of preterm infants are those of Kitchen from Melbourne ${ }^{3}$ and Brooke from London. ${ }^{4}$ Both of these cover the range 28 to 30 weeks (but not later): for this two week period their mean values accord well with those of Keen and also with the values shown in our 1971 charts.

Data from length (crown-heel) and head circumference are given by Kitchen for the period 28 to 30 weeks. ${ }^{3}$ Both sets of mean values are slightly (about $4 \%$ ) lower than those shown in our 1971 charts.

The charts have been revised (Castlemead Publications, Swains Mill, 4A Crane Mead, Ware, Herts 3G12 9PY) in the light of the recent studies quoted. Centiles 3, 10, 90, and 97 were derived from SDs when necessary. The most considerable change in the charts affects birthweights of preterm infants between 32 and 36 weeks' gestation.

\section{References}

1 Gairdner D, Pearson J. A growth chart for premature and other infants. Arch Dis Child 1971;46:783-7.

2 Keen DV, Pearse RG. Birthweight between 14 and 42 weeks' gestation. Arch Dis Child 1985;60:440-6.

3 Kitchen WH, Bajuk B, Lissenden JV, Yu VYH. Intrauterine growth charts from 24 to 29 weeks' gestation. Aust Paediatr J 1981;17:269-72.

4 Brooke OG, McIntosh N. Birthweights of infants born before 30 weeks' gestation. Arch Dis Child 1984;59:1189-90.

Douglas Gairdner and Julie Pearson 17 Rutherford Road, Cambridge CB2 $2 \mathrm{H}$

\section{Lesions in the neonatal brain}

Sir,

Rushton and colleagues are to be congratulated on their correlations between ultrasound scans and macroscopic postmortem pathology. ${ }^{1}$ Their suggestion that parenchymal lesions associated with subependymal/intraventricular haemorrhage are of secondary ischaemic nature is in accord with previous studies. ${ }^{2-4}$ Rushton et al have, however, failed to provide the histological evidence that would be needed to support their contention that the bleeding had occurred in all cases into an area of periventricular leucomalacia.

From our own studies into these lesions, Dr Pape and $I$ के suggested that the primary matrix bleed might well $\vec{\circ}$ obstruct the vein branches traversing the subependymal $\rightarrow$ matrix with consequent venous infarction. Such a sequence $\vec{\omega}$ would be favoured by an episode of hypotension after the initial bleed. Undoubtedly, some lesions occur, as de- ํㅡㅁ scribed by Rushton et al, by a process of severe ischaemia? due to hypotension followed by reflow and haemorrhage into the ischaemic tissue. This sequence could account for $\vec{N}$ separate but coincident bleeds into subependymal matrix and periventricular tissue.

To claim, as Rushton et al do, that all apparent parenchymal extensions of subependymal haemorrhage $\frac{1}{\sigma}$ are due to periventricular leucomalacia seems as simplistic윽 as the claim they incorrectly attribute to Pape and Wigglesworth that all subependymal/intraventricular $\vec{\nabla}$ haemorrhage is due to cerebral hyperperfusion.

The arrows loosed by Rushton and colleagues at current $\Phi$ views on pathophysiology of neonatal cerebral lesions might perhaps fly straighter if the missiles themselves were $\stackrel{\Phi}{-}$ correctly spelt (sagittal or parasagittal from 'sagitta', ฏू arrow: not saggital!).

J S Wiggleswor Royal Postgraduate Medical School, London W12 OHS

Dr Rushton and co-workers comment:

The omission of histological data was predicated in part by the authors' belief that microscopic examination of these lesions does not provide incontrovertible evidence as to the aetiology of the haemorrhagic lesions in the white matter and in part by limitations of space. Such arguments are perhaps more appropirate in a less clinical context. We do응 not claim, as Wigglesworth suggests, that all parenchymal $\frac{\Gamma}{0}$ extensions of subependymal/intraventricular haemorrhage 3 . lesions are due to periventricular leucomalacia but that the apparent ultrasonic 'extension of an intraventricular haemorrhage is more probably the result of haemorrhage into ischaemic periventricular tissue'. Such speculation may well extend beyond currently accepted data, as $D$ Levene emphasises in his commentary, but currently응 accepted data does not in our or your commentator's opinion completely resolve the interrelationship between $N$ subependymal/intraventricular haemorrhage and peri- $N$ ventricular leucomalacia.

We are fully aware of the pioneering work of Drs Wigglesworth and Pape in the study of hypoxic and ischaemic lesions of the brain. As we were unable toco discuss all the factors related to subependymal/intra- $\frac{C}{\Phi}$ ventricular haemorrhage our apparently over simplistic $\stackrel{\mathscr{\leftrightarrow}}{+}$ approach was based on one of the two models presented by Pape and Wigglesworth, ${ }^{3}$ one of which 'involves the effects 
of increased blood flow', the causes of which are multifactorial 'leading to breakdown of the blood brain barrier with resultant oedema or haemorrhage'. We do not, and cannot, exclude a possible role for venous infarction, though our emphasis is on ischaemic infarction. We are aware, however, of the limitations of both the clinical and pathological approach to neonatal neuropathology, and we are in complete agreement with Levene that resolution of these differences of opinion will largely depend on more sophisticated techniques that allow the study of the genesis and evolution of the lesions during life.

As to the direction of our arrows we were unaware of any correlation between either the name or spelling of these missiles and the accuracy of their flight, though we cannot deny our spelling error.

\section{References}

${ }^{1}$ Rushton DI, Preston PR, Durbin GM. Structure and evolution of echo dense lesions in the neonatal brain. A combined ultrasound and necropsy study. Arch Dis Child 1985;60: 798-808.

2 Wigglesworth JS, Pape KE. An integrated model for haemorrhagic and ischaemic lesions in the newborn brain. Early Hum Dev 1978;2:179-99.

3 Pape KE, Wigglesworth JS. Haemorrhage, ischaemia and the perinatal brain. (Clinics in developmental medicine, nos 69-70). London: Heinemann and Spastics International Medical Publishers, 1979.

4 Volpe JJ, Herscovitch P, Perlman JM, Raichle ME. Positron emission tomography in the newborn. Extensive impairment of regional cerebral blood flow with intraventricular haemorrhage and haemorrhagic intracerebral involvement. Pediatrics 1983;72:589-601.

\section{Plasma concentrations after oral or intramuscular vitamin $K_{1}$ in neonates}

Sir,

We were interested to see the article by McNinch et al ${ }^{1}$ regarding plasma concentrations of vitamin $\mathrm{K}_{1}$ in neonates. Their data clearly show that after a pharmacological dose of vitamin $\mathrm{K}_{1}$ : (1) plasma concentrations of vitamin $K_{1}$ are considerably higher after intramuscular than oral administration; (2) there is considerable interindividual variation in plasma vitamin $K_{1}$ concentrations both after oral and intramuscular administration; and (3) the minimum plasma concentrations of vitamin $\mathrm{K}_{1}$ achieved are considerably higher after intramuscular administration $(\approx 300 \mathrm{ng} / \mathrm{ml})$ than oral administration $(0-4 \mathrm{ng} / \mathrm{ml})$.

If prophylactic treatment is to be given to prevent haemorrhagic disease of the newborn then it needs to be effective in all babies. Thus the minimum plasma concentration achieved is more important than the median plasma concentration. In the two babies in whom vitamin $\mathrm{K}_{1}$ was not detectable after oral administration the authors state that it was possible that sufficient vitamin $K_{1}$ was absorbed and that neither baby developed haemorrhagic disease of the newborn. Firstly, it is unlikely that either baby would develop haemorrhagic disease as the incidence is so low. Secondly, as the plasma concentration of vitamin $\mathrm{K}_{1}$ required to ensure adequate clotting factor synthesis in the newborn is not known the authors cannot conclude that their practice of administering oral vitamin $K_{1}$ is safe.

Oral vitamin $K_{1}$ is possibly an effective prophylaxis in all healthy babies. Until the minimum plasma concentration of vitamin $\mathrm{K}_{1}$ required has been determined, however, and this has been shown to be achieved in all babies after a single oral dose of vitamin $K_{1}$, then routine oral vitamin $K_{1}$ cannot be justified. As haemorrhagic disease of the newborn is a life threatening condition the data presented by McNinch et al support the routine administration of intramuscular vitamin $\mathrm{K}_{1}$ to all newborn babies. The extra cost involved is minimal, and also the incidence of adverse reactions to intramuscular vitamin $K_{1}$ is negligible.

\section{A Choonara and B K Park The University of Liverpool, Liverpool L69 $3 B X$}

\section{Dr McNinch and co-workers comment:}

We thank Drs Choonara and Park for their interest. We were careful not to suggest that our absorption study proved the administration of oral vitamin $\mathrm{K}_{1}$ to be 'safe' in the sense of providing certain prophylaxis against haemorrhagic disease of the newborn. The efficacy of prophylaxis can be shown only in clinical practice, but evidence so far strongly suggests that a $1 \mathrm{mg}$ oral dose of vitamin $K_{1}$ is effective. In 1982 Dunn $^{2}$ reported one case of haemorrhagic disease of the newborn among 31000 babies receiving such prophylaxis and has seen no further case since (personal communication). In Exeter we have seen no case in some 12000 babies since adopting the policy outlined in the paper. As clearly stated, we believe that our results together with reported clinical experience 'give support to the practice of using oral prophylaxis in well, mature babies', but further research is necessary to determine the optimal dose.

Regarding the two babies in whom vitamin $K_{1}$ was not detected, we suggested that sufficient vitamin $K_{1}$ might have been absorbed 'to raise the plasma value well beyond endogenous concentrations'- that is, beyond the estimated cord blood concentration of $0.02 \mathrm{ng}-\mathrm{ml}^{3}$ - the limit of detection in the babies concerned being 4 and $10 \mathrm{ng} / \mathrm{ml}$. If the babies had developed haemorrhagic disease of the newborn it would have been mandatory to say so; we thought it relevant to state that they did not. We agree that it would be of great interest to determine 'the minimum plasma concentration required' to prevent the disease but suggest that no ethical study could achieve this. At present the best guide we have is the normal adult plasma concentration of vitamin $\mathrm{K}_{1}(0 \cdot 1-0.7 \mathrm{ng} / \mathrm{ml}) .^{3}$

Finally, we do not believe that cost is the main reason that prophylaxis is not given to every baby. Parents rightly question the need for an injection in their well babies, some seeing it as unnecessary medical interference, and it is not totally without risk. ${ }^{4}$ Many maternity units currently give intramuscular prophylaxis only to a minority of babies, those considered most at risk from the disease. We hope that our paper will encourage them to give prophylaxis orally to the remainder who would otherwise receive none. 